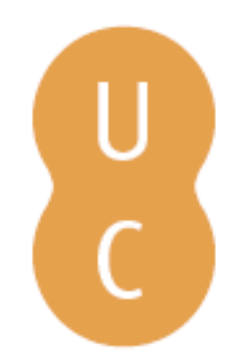

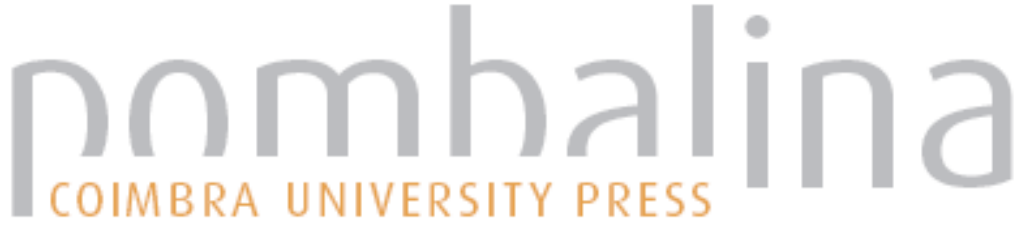

\section{A ética como objeto de ensino}

Autor(es): $\quad$ Oliveira, Luís Adriano; Afonso, José Luís

Publicado por: Imprensa da Universidade de Coimbra

URL

persistente: URI:http://hdl.handle.net/10316.2/38810

DOI: $\quad$ DOI:http://dx.doi.org/10.14195/978-989-26-1123-5_6

Accessed : $\quad$ 26-Apr-2023 02:29:40

A navegação consulta e descarregamento dos títulos inseridos nas Bibliotecas Digitais UC Digitalis, UC Pombalina e UC Impactum, pressupõem a aceitação plena e sem reservas dos Termos e Condições de Uso destas Bibliotecas Digitais, disponíveis em https://digitalis.uc.pt/pt-pt/termos.

Conforme exposto nos referidos Termos e Condições de Uso, o descarregamento de títulos de acesso restrito requer uma licença válida de autorização devendo o utilizador aceder ao(s) documento(s) a partir de um endereço de IP da instituição detentora da supramencionada licença.

Ao utilizador é apenas permitido o descarregamento para uso pessoal, pelo que o emprego do(s) título(s) descarregado(s) para outro fim, designadamente comercial, carece de autorização do respetivo autor ou editor da obra.

Na medida em que todas as obras da UC Digitalis se encontram protegidas pelo Código do Direito de Autor e Direitos Conexos e demais legislação aplicável, toda a cópia, parcial ou total, deste documento, nos casos em que é legalmente admitida, deverá conter ou fazer-se acompanhar por este aviso. 


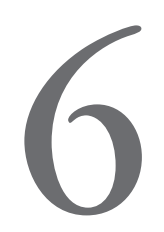

\title{
A ÉTICA COMO OBJETO DE ENSINO
}

\author{
Luís Adriano Oliveira \\ Prof. do Departamento de Engenharia Mecânica \\ da Universidade de Coimbra (DEMUC)
}

José Luís Afonso

Provedor do Estudante da Universidade

de Coimbra e Prof. do DEMUC

bttp://dx.doi.org/10.14195/978-989-26-1123-5_6 
(Página deixada propositadamente em branco.) 
Deve a ética ser ensinada ao longo da formação curricular de um estudante de nível superior, universitário ou politécnico? A questão não é consensual e merece ponderada reflexão.

Dependendo das circunstâncias em apreço - logísticas, curriculares, ou outras - o ensino de ética a estudantes de nível universitário ou politécnico pode assumir diversos formatos: disciplina específica inserida na estrutura curricular; parte do programa de unidade letiva mais abrangente; workshop; conferência ou videoconferência; seminário; curso; colóquio; ou simples debate, eventualmente promovido por estrutura representativa dos próprios estudantes.

É, hoje, unanimemente reconhecida a imperiosa necessidade de respeitar e fazer respeitar princípios de conduta ética na vivência corrente da sociedade, em geral, e, por inerência, na prática quotidiana do ensino superior, objeto central do presente seminário. Menos consensual será, entretanto, a necessidade - ou sequer a conveniência - de conferir estatuto autónomo ao ensino de ética a estudantes de nível superior.

Nomeadamente, vozes críticas do ensino explícito de ética a jovens universitários avançam argumentos como (Elliott e Stern, 1997; Oliveira, 2013): trata-se de estudantes adultos, de formação moral e ética já consolidada, pouco recetivos, portanto, a alterações comportamentais significativas; o ensino de ética tem base essencialmente genérica e teórica, enquanto a prática quotidiana suscita problemas específicos, que requerem soluções concretas; normatização excessiva retira espaço à criatividade; a conduta ética no quotidiano universitário é apenas uma particularização da conduta ética na vida, sendo que proscrever atitudes eticamente condenáveis decorre do simples 
exercício de bom senso; o tempo gasto na estruturação do que se entende por boas práticas será mais rentável se diretamente investido na concretização dessas boas práticas.

Argumentos defensáveis, sem dúvida! Porém, a simples análise dos dois estudos de caso a seguir apresentados, e de tantos outros que a realidade vivida no ensino superior poderá trazer a este debate, convidam a breve exercício de reflexão acrescida.

I) - Estudo de caso relatado por Oliveira (2013). "Em outubro de 2008, integrei um júri de dissertação de mestrado em engenharia mecânica. A dissertação tinha por tema a ventilação natural em espaços de trabalho e o candidato, José Tomás ${ }^{20}$, apresentara um trabalho que o júri considerou, de forma unânime, de muito boa qualidade. Durante as provas, porém, o examinador externo, Prof. Manuel Campos, comentou: "Ao ler, pela primeira vez, a página 34 da sua dissertação, fui invadido por uma estranha sensação de déjà $v u$. Mais tarde, voltei a ela e fez-se luz: essa página reproduz fielmente, embora sem qualquer sinal de citação, texto da minha própria tese de doutoramento. Tem consciência da gravidade de um ato de plágio como este?" Resposta do candidato: "Admito esse facto. Confesso que reproduzi o texto porque me pareceu muito oportuno e que me esqueci de referir a fonte. Na verdade, não fazia ideia de que essa omissão fosse assim tão grave!"

Pessoalmente, acreditei na sinceridade da resposta. De facto, nessa altura a sensibilização dos alunos para a questão ética limitava-se essencialmente a comunicar-lhes que não deviam "copiar" nos exames!

20 À exceção dos dois coautores do presente texto, todos os nomes aqui referidos são, naturalmente, fictícios. 
José Tomás foi significativamente penalizado, tendo obtido o grau de Mestre com a classificação mínima. Hoje, de forma mais ou menos estruturada, existe já a preocupação de incutir princípios éticos ao longo da formação curricular. Alertados que estão os alunos para a problemática da usurpação de autoria, José Tomás teria, no mínimo, sido reprovado."

II) - Desde longa data, a cadeira de Mecânica dos Fluidos, ministrada no Departamento de Engenharia Mecânica da Universidade de Coimbra (DEMUC), vem adotando a prática de disponibilizar aos alunos, via Internet, proposta de resolução de todas as questões formuladas em provas escritas (testes, frequências, exames finais...) destinadas a avaliação curricular. A resolução avançada não é, obviamente, a única possível: trata-se apenas de um exemplo de resposta que, na ótica do docente, mereceria cotação máxima.

Em avaliação recente, o exame de época de recurso continha uma pergunta já formulada oito anos atrás. Enquanto resposta a essa questão, um aluno reproduziu textualmente a proposta de resolução que tinha sido, à época, disponibilizada.

Como deverá o docente reagir, perante tal situação?

A dedicação de um espaço próprio ao ensino de ética teria, porventura, evitado a ocorrência das duas falhas comportamentais acima relatadas.

Não se preconiza, aqui, a leitura acrítica de "compêndios" sobre o assunto, ou de textos normativos mais ou menos diretamente aplicáveis. Pelo contrário, em nosso entender, o estudo de ética deverá centrar-se essencialmente na discussão de casos práticos, envolvendo mesmo a ocorrência de dilemas éticos. Nesse espaço dialogal, 
dinamizado e assistido pelo docente, e fundamentado na legislação aplicável (leis gerais, estatutos, regulamentos, normas, declarações de ética, códigos de conduta, textos de apoio...), cada aluno terá oportunidade de testemunhar o seu ponto de vista, expor as suas dúvidas ou perplexidades, sugerir formas de detetar, prevenir ou evitar a ocorrência de condutas eticamente questionáveis ou mesmo censuráveis, refletir sobre a melhor forma de reagir face ao não respeito das boas práticas.

Com efeito, nem sempre é óbvia, para um jovem universitário, a distinção entre: (i) - moral, ética, deontologia; (ii) - erro honesto, erro por negligência ou por incompetência, erro fraudulento [fabricação, falsificação, plágio (FFP)]; (iii) - conflitos de interesse, conflitos de compromisso; (iv) - boas práticas, práticas questionáveis, práticas censuráveis; (v) - denúncia interna, denúncia externa; (vi) - repreensão oral, repreensão escrita, sanção, processo disciplinar.

Como refere Oliveira (2013), as instituições federais americanas National Institutes of Health (NIH) e Alcohol, Drug Abuse, and Mental Health Administration (ADAMHA) condicionam a concessão de financiamento a programas de formação em biomedicina à garantia de que tais programas incluam instrução sobre "conduta responsável na investigação" (NAS, NAE E IOM, 1992). A crescente ocorrência de situações de natureza conflituosa decorrente de falhas éticas, que se vem registando na última década, no seio da comunidade universitária, permite antever que tal exigência de formação ética tenda a estender-se à escala planetária.

Em Portugal, nomeadamente, é notório o esforço de regulamentação que diversas entidades de ensino superior vêm desenvolvendo, com particular incidência para a elaboração de declarações de ética e de códigos de conduta.

Refletir sobre tais textos normativos, em espaço próprio dedicado ao ensino de ética, não tem por finalidade desafiar ou sequer questionar a formação humana de jovens adultos que são os estudantes 
do ensino superior. Pelo contrário, trata-se, sim, de refletir sobre a forma mais adequada de colocar essa formação ao serviço da sua vocação universitária, responsável, ao mesmo tempo que se procura promover a consciencialização para os problemas - de consequências não raro graves - que podem advir de práticas eticamente questionáveis ou mesmo censuráveis. Mais do que encarar os textos normativos como "receituários" a seguir de forma acrítica ou a aplicar cegamente, procura interiorizar-se o respetivo conteúdo, aplicando-o a casos concretos, notando que um mesmo problema de natureza ética pode conduzir a diversas soluções igualmente respeitáveis, fruto do enquadramento geográfico, científico, cultural, financeiro ou, simplesmente, temporal.

Usando a terminologia proposta por Figueiredo (2009), trata-se, em essência, de utilizar a ética normativa na promoção do que realmente se procura alcançar: a ética da responsabilidade.

A experiência que os autores deste texto vêm acumulando sobre o ensino de ética na formação universitária é, de resto, eloquente: de um modo geral, os estudantes reagem de forma claramente encorajadora, testemunhando confiança acrescida para encarar o seu quotidiano universitário, e maior sentido de responsabilidade para gerir a vertente ética inerente a esse mesmo quotidiano. Testemunho igualmente gratificante é partilhado por diversos autores/professores, nomeadamente Elliott e Stern (1997), Figueiredo (2009), ou Stewart (2011).

Pode, mesmo, sugerir-se a inclusão de matéria afim em espaço letivo opcional do último ano curricular do ensino secundário. Naturalmente adaptado às condições concretas vigentes, tal ensino de ética seria uma primeira sensibilização para o futuro percurso universitário ou politécnico, ou ainda, não sendo esse o caso, para o seguimento responsável de qualquer via profissionalizante.

Em conclusão, se o ensino de ética for encarado como espaço de diálogo centrado em questões concretas ilustrativas, onde ética normativa se conjuga com ética da responsabilidade, com claro 
predomínio para a segunda, então o espaço letivo dedicado ao ensino de ética assume a dimensão de investimento estratégico, e a resposta à questão inicialmente formulada é claramente afirmativa.

\subsection{Referências Bibliográficas:}

Elliott, D. e Stern, J. E. (Orgs.) (1997), Research Ethics: A Reader. Hanover, NH: University Press of New England for the Institute for the Study of Applied and Professional Ethics at Dartmouth College.

Figueiredo, A. D. (2009), Uma experiência do ensino da ética a futuros profissionais de tecnologias da informação. Signo y Pensamiento, 28(55), pp. 152-162.

NAS, NAE, IOM - NATIONAL ACADEMY OF SCIENCES, NATIONAL ACADEMY OF ENGINEERING, INSTITUTE OF MEDICINE (1992), Responsible Science: Ensuring the Integrity of the Research Process (Volume I). Washington, D.C.: National Academy Press

Oliveira, L. A. (2013), Ética em Investigação Científica. Lisboa: Lidel - Edições Técnicas, Lda.

Stewart, C. N. Jr. (2011), Research Etbics for Scientists: a Companion for Students. West Sussex, UK e Hoboken, NJ: Wiley-Blackwell - John Wiley \& Sons, Ltd. 